\title{
Panel on: Maintaining Identity in the Virtual World
}

\begin{abstract}
Being able to establish and maintain an identity on the virtual world is becoming an increasingly important issue in the twenty-first century. These presentations address this critical issue from three perspectives: virtual identity fraud, virtual social support, and access to virtual communication technologies.
\end{abstract}

\section{Proposed Panelists}

\section{Xin-An Lu, Shippensburg University of Pennsylvania and Jun Yang, Bloomsburg University of Pennsylvania}

\section{xalu@wharf.ship.edu bettyjuny@yahoo.com}

\section{Topic: "Virtual Fraud": Misinformation in the New Age}

Summary: Naturally, humans seek physical and psychological joy. Romance, for instance, is one of the means. People are making quick use of the Internet technology to facilitate their seeking of romantic and quasi-romantic experience via "virtual reality." Based on statistics, interviewee responses, testimonies, reports, and anecdotes, this discussion illustrates that virtual reality frequently turns on to be a virtual illusion. The discussion also explores the psychological impact that "virtual illusion" has on the participants.

\section{Leena Mikkola and Mikko Jäkälä, University of Jyväskylä, Finland}

\section{leena.mikkola@jyu.fi mikko@cc.jyu.fi}

\section{Topic: Technologies as a Platform for Support}

Summary: Support is a concept that is used in the contexts of both communication and technology. In the context of communication support refers to interpersonal relationships and possible outcomes of support. In the technological context support usually refers to different technical solutions that enable mutual communication and cooperation for individuals, groups and organizations. Support as a communicative phenomenon, refers to a communication process in which support emerges in interaction and the participants create the supportive and support-seeking messages. This presentation discusses the phenomenon of support in both contexts.

\section{Md Shahid Uddin Akbar, Coordinator, ICTDP'B, Bangladesh}

\section{Topic: Alternate Connectivity Solution: Critical Challenge for Developing Coun- tries}

Material published as part of these proceedings, either on-line or in print, is copyrighted by Informing Science. Permission to make digital or paper copy of part or all of these works for personal or classroom use is granted without fee provided that the copies are not made or distributed for profit or commercial advantage AND that copies 1) bear this notice in full and 2) give the full citation on the first page. It is permissible to abstract these works so long as credit is given. To copy in all other cases or to republish or to post on a server or to redistribute to lists requires specific permission from the publisher at Publisher@InformingScience.org
Summary: ICT can open new channels that bring new knowledge and information resources to rural communities. Traditional communication channels have been used successfully but there have been monologic and have not allowed for much interaction with users. 
To ensure the connectivity, physical accessibility is a must and Telecenter can be the role module and the need may be met as physical access center. The educational institutes (Schools/Colleges)/ local offices of the civil society (NGO) having minimum ICT facilities (Computer \& printer ).

\section{Nuria W. Soeharto, Jakarta, Indonesia}

\section{Topic: Silent Language on the Net}

Summary: This paper is about the importance of understanding people's culture in order to avoid any communication failure. In this superhighway era, this understanding still needs to be applied to the interaction in cyberspace where computer screens these days can be seen as the only common space of world-wide interaction. This paper begins by presenting personal interaction on experiencing cultural difference which leads to the works of Edward T. Hall on the next part. Then, allowing Hall's theory to the net, the paper continues with a picture of media coverage regarding the actual incident in Bali, Indonesia, and ends by discussion. 